Session 2470

\title{
Learning from our Minority Engineering Students: Improving Retention
}

\author{
Maria A. Reyes, Mary R. Anderson-Rowland, Mary Ann McCartney \\ Arizona State University
}

\begin{abstract}
Since the summer of 1996, the Minority Engineering Program (MEP) at Arizona State University (ASU) has directed an MEP Summer Bridge Program for students entering the College of Engineering and Applied Sciences (CEAS) in the fall semester. Participating students compete in teams for scholarships as they learn how to cope with the difficult introduction to engineering course. A requirement for the scholarship is attendance in the fall Academic Excellence class (2semester hours credit). Approximately 40 students have attended the bridge program each year and their one-year retention is significantly higher than the retention of minority students who do not attend the bridge program or of non-minority engineering students.
\end{abstract}

Focus groups were held with a sample of these bridge students to understand factors that have helped in their retention and also to identify factors that made retention difficult. The students related the reasons why they attended the bridge program, how the program helped them decide to major in engineering at ASU, how the bridge program affected their start as a freshman, and how the Academic Excellence class assisted them in remaining as a student in engineering. The students also related situations that made matriculation as an engineering student difficult. Some of the information received from these students has produced changes in the academic system to increase retention of underrepresented minority students.

The paper gives additional insights as to how minority engineering students fare in academia and how this information can be used to improve their retention and the academic system in which they are immersed.

\section{Introduction}

There is an absolute need for diversity in engineering. For some time, the recruitment of underrepresented minority students to engineering has been recognized as the right or fair thing to do. To not include women and underrepresented minorities in engineering is a waste of brainpower. However, in the last several years, industry has realized that a diverse engineering workforce is a necessity. A diverse team of engineers will come to a better solution than a team that thinks and acts alike. More women and minority engineers are needed in order to meet the demands for a larger engineering workforce. A diverse engineering workforce is needed for the global market that includes customers from around the world, as well as industry plants located off shore. Additionally, providing a supportive environment for diversity is good business: all employees benefit. 
College enrollment and degree attainment by minorities have been increasing over the last two decades. Although minority enrollment in undergraduate programs dropped in the early 1980s, it has been steadily increasing since 1984 , both in numbers and as a percentage of total undergraduate enrollments. In 1984, underrepresented minorities were 14.6 percent of all undergraduate students; by 1994, they were 20.6 percent [1]. However, with the exception of Asians, minorities are a small proportion of scientists and engineers in the United States. Asians were 10 percent of scientists and engineers in the United States in 1995, although they were 3 percent of the U.S. populations. Blacks, Hispanics, and American Indians, as a group, were 6 percent of the total science and engineering labor force in 1995 and 23 percent of the U.S. population. Blacks were 3 percent, Hispanics were 3 percent, and American Indians were less than 1 percent of scientists and engineers [2].

Relative to the Arizona census, the percent of underrepresented minority engineering undergraduate students in the College of Engineering and Applied Sciences (CEAS) at Arizona State University (ASU), is doing somewhat better than these national statistics. Since 1991, the number of underrepresented undergraduate minority engineering students has grown from 315 (10\%) to around 650 in $1999(16 \%)$. See Table 1 for the relative parity of CEAS engineering students to the Arizona population.

\begin{tabular}{|l|c|c|c|c|cc|}
\hline & $\begin{array}{c}\mathbf{1 9 9 6} \\
\text { US }\end{array}$ & $\%$ & CEAS & \% & $\begin{array}{l}\text { Arizona } \\
\text { Census } \\
(\mathbf{1 9 9 8})\end{array}$ & $\begin{array}{c}\text { Parity } \\
\text { (Relative } \\
\text { CEAS) }\end{array}$ \\
\hline Women & 67,618 & 19.0 & 832 & 20.5 & $50.5 \%$ & 40.6 \\
African Americans & 24,922 & 7.0 & 111 & 2.7 & $3.6 \%$ & 76.1 \\
Hispanic American & 26,483 & 7.4 & 438 & 10.8 & $22.1 \%$ & 48.9 \\
Native American & 2,396 & 0.7 & 97 & 2.4 & $5.5 \%$ & 43.6 \\
\hline
\end{tabular}

Table 1. Relative Parity of the numbers of CEAS underrepresented minority students to the Arizona minority population.

Although the CEAS is doing quite well in increasing the enrollment of underrepresented minority students in engineering, our goal is to do much better.

\section{Office of Minority Engineering Programs}

Since 1993, a very active and dedicated Office of Minority Engineering Programs (OMEP) has been recruiting and supporting ethnic minority students, who are underrepresented in engineering. The Office has developed a pathway of outreach and support programs that begin at the junior high level and continue through high school (the Math, Engineering, Science Achievement (MESA) Program serves these two levels), and then feed into the Summer Bridge Program sponsored by the MEP for new freshmen engineering students. During their college years, the MEP serves as a major support of these students. The MEP supports the three minority student organizations of the American Indian Science and Engineering Society (AISES), the National Society of Black Engineers (NSBE), and the Society of Hispanic Professional Engineers (SHPE). A room is maintained by the OMEP for the use of AISES, NSBE, SHPE, and all underrepresented minority engineering students. The room was named the 
CEMS (Coalition of Minority Societies) Center and is pronounced "seams" as in a seam binding together different pieces of cloth to make one garment.

Research has shown that the key actions for retention of minority and non-minority engineering students includes: institutional commitment as measured by attitudes of faculty and staff, integral minority engineering programs, allocation of resources, focus on removing barriers to student success, special attention paid to the early success of freshmen, and the delivery of special programs designed to help make the institution more supportive [3]. The CEAS Office of Student Affairs is engaged in all of the above key actions. This paper will now focus on one of these programs, the summer bridge program offered by the CEAS Minority Engineering Program. The program has been supported by the Foundation Coalition, the Western Alliance to Expand Student Opportunities, and Boeing/McDonnell Douglas. There is no program fee for the bridge participants.

Since ASU is a public institution, the acceptance rate of all freshman students who apply is approximately $80 \%$. Along with that high acceptance rate, the retention rate of first year students to ASU and to the CEAS are relatively low. ASU, as a university, used the first-time, full-time, freshman students of the entering class of fall 1994 as their benchmark for one-year retention of freshman. This freshman cohort had a $68 \%$ one-year, retention rate. The University set a goal of one-year retention at 78\% for first-time, full-time freshman entering in the fall 2003. The one-year retention rate of the fall 1998 freshman cohort is 75.2\% [4]. In comparison, the engineering freshman cohort of 1994 had a $69 \%$ one-year, retention rate to the university and a $58 \%$ one-year, retention rate to the CEAS. The fall 1998 engineering freshman cohort had a $74.4 \%$ retention rate.

There has been a marked increase in the one-year, retention rate of underrepresented engineering minority students at both the University and the CEAS level since 1996, when the first MEP Summer Bridge Program (SBP) was held.

\section{MEP Summer Bridge Program}

The MEP Summer Bridge Program, begun in the summer of 1996, has been a particularly successful program in terms of retaining students both in the university and in the college after the first year. The participants in the two-week summer residential program are entering CEAS freshman for the following fall. Program participants must be admitted into the CEAS at ASU. Participating students compete in teams for scholarships (ranging from $\$ 800$ - $\$ 2,000$ ) as they are learning strategies and skills that will give them a "head start" with the difficult introduction to engineering course required of all engineering students. A feature of the program is that engineering students deliver the curriculum [5]. An additional requirement for the scholarship is registration and participation in the ASE 194 Academic Excellence class (2-semester hours credit) in the fall semester. Approximately 40 students have attended the bridge each yea (approximately one-third of the underrepresented minority students in the freshman class) and their one-year retention is higher than the retention of minority students who do not attend the bridge program and of non-minority engineering students. For more information about the MEP Summer Bridge Program, see References 6 and 7. 
The participants of the MEP Summer Bridge Program are being retained at a rate of over $80 \%$ at the University level (exceeding the Fall 2003 goal of 78\%) and at over 75\% in the CEAS. By way of comparison, for the Fall 1995 engineering minority student freshman cohort, retention after one year was $69.2 \%$ at ASU and 58.2\% in the CEAS. Since the program has now been in existence for four years, we thought that it would useful to hold focus groups with some of the students from each of the past three bridge programs. We were primarily interested in their thoughts about retention and how the bridge program had helped them to stay enrolled. In the course of the three focus groups, we were surprised to learn of some of the influences on the decision making of the students to enroll in engineering, to enroll in the CEAS, and to stay enrolled in the CEAS.

\section{The Focus Groups}

The reasons for the success of the students in the MEP SBP is obviously related to the program, however, it is interesting to look at the diversity of the student's academic backgrounds from all three years and to try to discern what actual factors are encouraging their success. The authors have attempted to discover the factors through a series of focus group sessions with each of these student sets [6].

The focus groups sessions were announced at a celebratory dinner sponsored by the MEP for the participants from all three programs. The purpose of the celebration was to convey to the students the findings and success rates and announce that the MEP would be instituting a continuing scholarship program for past participants of the MEP SBP. (The scholarships awarded during the SBP were one-time grants they received during their first year.) At this dinner the participants were asked to fill out a general questionnaire about the SBP. The responses (25) came from a range of participants from each of the three years [6]. From the students that completed the surveys, three focus groups were scheduled, one for students from each year of the program. At each focus group meeting, the students were asked to answer similar questions in a group setting and were allowed to include any information that they wished to share.

\section{Survey Results}

In summary, the survey showed that the MEP SBP students overall rating of the program was 9.09 on a scale of 1 to 10 , with 10 being the highest score. Some of the most often mentioned highlights of the program included meeting new people, exposure to ASU, and the experiencing of college and residential life. All of these factors would help make a student less marginalized. When asked if the MEP SBP efficiently prepared them for the incoming year, the students responded with an 8.64 average. When asked if the program had any effect on their decision to pursue or to continue pursuing as engineering degree, all but one of the students answered "yes." Individuals said that the program helped them switch majors within the CEAS, made them want to do more, helped them find friends for excellent study group members, and gave them a sense of security of having a group that they could always go to. The program also helped them to see the whole picture of what an engineer is [6]. A lack of the whole picture is a common reason that students drop out of engineering and science [8]. Students also mentioned that the SBP reinforced their decision to study engineering and for others, the program reaffirmed their 
decision to come to ASU. All of the students also felt that the teaming activities of the program were helpful [6].

\section{Summer '96 Focus Group}

The '96 focus group consisted of three junior (or third year) students including once Hispanic female, one Hispanic male, and one Native American female. These students felt that the most helpful part of the SBP were the team building aspects of the program. They felt that the activities of the program gave them a "head start" for their first semester. All of these students tired working during their second year and all of them had their GPA go down. They say that they are still trying to recover the loss of GPA. Each one had at least one parent that did not go to college and receive a degree [6]. A closer examination at each of the students gives a more accurate accounting of the effect of the SBP and other supports that the students have experienced at ASU.

Alfredo had two non-minority roommates that did not return to the CEAS after the first year, one because of his academic performance and the other because he found that aerospace engineering "wasn't for him", so he left for Northern Arizona University (NAU) and is studying Accounting. Alfredo stated that in spite of these friends leaving engineering and ASU, he did not drop out because of family support and sheer determination. Alfredo knew in high school that he wanted to be an engineer through the help of his guidance counselor and ASU (SHPE) students who went to visit his school in Yuma, Arizona (3.5-hour drive from the university). He had always been good in math and science and had done some research at the library about robotics. Scholarships from ASU and the MEP SBP helped make sure that ASU was the university he attended.

Isabel thoughts were about ECE 100, the introductory engineering course. She said the class was a deterrent from engineering and that the only thing that helped was the tutoring from Abel (an MEP student tutor). She thought that the modeling portion of the class was the worst and that the group projects were hard. Isabel would have never considered ASU without the MESA (Mathematics, Engineering, and Science Achievement) program and knew wholeheartedly that the SBP solidified her coming to ASU.

Kristina is also a former MESA student. She joined MESA her freshman year at Window Rock High School on the Navajo Reservation in Northern Arizona. She said that a trip to ASU with the MESA program and a CEMS Panel member, who was in AISES and in aerospace engineering, helped influence her decision to pursue the same degree. However, the biggest influence on her decision to be an engineer was her MESA advisor. She advised that the most important thing, especially with Native American students, is getting them on campus to ASU. Kristina credits the SBP in helping her make the decision to come to ASU. She was the current president of AISES at the time of the focus group and has found a lot of support and encouragement for her leadership role from the MEP. She has now been elected as one of the top three national student officers for AISES National

All three students started out in the honors program and felt that to begin with, the extra work that the Honor's College requires did not tie into engineering, it was mainly social science type 
work. Isabel pointed out as well that, "over here (at the MEP) everyone thinks so much differently, and I like that [6]."

\section{Summer '97 Focus Group}

The second focus group consisted of three sophomore (or second year) students, all male Hispanic students. One of the students is also visually impaired and legally blind. All of these students are the first in their families to attend a four-year institution. These students all felt that they were still in school due to the strong support of their families and of the MEP SBP "family." Although difficult at the time, they realized that being forced to work on a team, not of their choosing, was an excellent experience that better prepared them for engineering at ASU [6]. Each student gave additional insights into their journey as an engineering major.

Brian lived in one of the dorms that had half of a floor dedicated only to engineering students. He said that it was really disturbing to see how the students from the other half of the floor do not have that much "stuff to get done for school" like he does. He also said that it was really helpful to know that down his hall there were other students studying at night and on the weekends like he did. Brian stated that he is the first in his family to attend college. He spent his first semester at ASU working 15-17 hours/week and taking 14 credit hours. Learning how to develop a design notebook during the MEP SBP helped out a lot. Otherwise, he could have felt lost like the rest of his ECE 1000 class who did not know what the teachers wanted in documentation. Also by using the computers during the MEP SBP he realized that a computer major was not for him. From his academic preparation prior to college he said that he felt that his senior year of high school was easier than the other years. He received an A in Math 270, the first calculus class for engineering students, and added that the MEP Academic Excellence Seminar aided him in getting this grade. Brian feels that due to the Foundation Coalition course work, and some of his extracurricular activities he can not be active in MEP.

Manny thinks that the engineering dorm floor was the best hall. He also feels that since he is the first generation out of his family going to college, his parents are very supportive and committed to his education. He feels that through a strong commitment to himself, he will be an engineer and this will allow him to do want he wants to do in his career. Going to high school, even though he had very little exposure, he liked computers a lot. He also feels that the CEAS environment is free of discrimination. He also stated that he has never felt the need to see his faculty professors. He feels that the MEP SBP gave him a head start in ECE 100, but he would have liked the program to include more on corporate politics and culture.

Ken is a commuter student and usually leaves school when his ride has to leave, but he likes to work in study groups. He is dependent on a ride since he is legally blind. He really appreciates the CEMS room as a place for him to study during the day. His father only finished high school and his mother completed junior college. He thinks that the program helped him learn to work in teams and introduced him to the Web and HTML. He thinks that maybe living on campus might be better because once you get home you forget about campus and time is wasted driving back and forth. He thinks that the key to his success in Math 270 (A) was sticking together and taking clustered classes. He stated that most of the MEP SBP participants that did not stick together are the ones that ended up dropping out. 


\section{Summer '98 Focus Group}

The third focus group consisted of six freshman (in their second semester) students, three Hispanic females, one Hispanic male, one African American female, and one Native American male student. These students were very energetic and talkative. They felt that just coming together in a focus group was very helpful to them. They felt that the SBP prepared them very well for the rigors of their first year as an engineering student. Even though they still have some doubts about making it as engineers, the all expressed that they would not be as committed to engineering if they had not had the SBP and the CEMS Center (and its visitors) as support [6].

Aurora is the first one in her family to go to college. She is the oldest of five and feels of pressure to stay motivated and to serve as a role model. She also thinks that since her parents did not go to college they can not understand why she can not get grades like those she got in high school, causing her a lot of emotional stress. She also stated that taking a small engine class in high school got her interested in mechanical engineering, but her high school counselor misadvised her by telling her that engineering was not for women. After participating in the MEP SBP, she not only felt very sure about ASU, but also about studying engineering. Aurora thinks that by participating in ASE 194 she felt forced (in a positive way) to get more involved in the campus organizations that helped her build her own community of friends. She summarized by saying that she still feels that she is not using all of her resources to the fullest and that once she does she will get a lot more out of the CEAS experience.

Anomie felt that her bad experience in MAT 270 hurt her self-confidence and almost made her change her degree. Anomie feels that the MEP SBP instructors influenced her so much that she still seeks their help in the academic and personal levels. The MEP SBP helped her build community and within this community she has found the support and motivation she needs to keep on going. She feels so strongly about the MEP and the CEMS students that without them she would not have such a good outlook. Anomie stated, "I would be depressed, it means so much to be able to know people and say 'hi'."

Sally, as a commuter student, spends about 50 minutes on the road everyday, but that does not keep her from being very involved in CEMS and WISE. Sally is the first in her family to go to college. Although she always felt very strong about ASU, it was not until she had contact with industry and participated in the bridge that she broke the stereotype she had about engineers and decided to pursue an engineering degree. She also thinks that the CEMS students make things seem a lot more bearable.

Sam works 20 hours a week, takes 14 credit hours, and participates in study groups. Even though his parents attended college, neither finished their degrees. They advise Sam to use his time wisely. He feels the ASE 194 seminar helped him improve on his study habits and time management skills. He likes to interact with the CEMS students and does not feel intimidated by the racial differences to the point of feeling that without them he would have lost his motivation to study. He says that by visiting the ASU computer engineering web page and reading about the hi-tech facilities of the CEAS, he decided on ASU. The MEP SBP was a plus and the scholarships awarded during the program also helped him tremendously. 
Felipe feels, that even though his parents did not go to college, they are very understanding of his needs. In addition, his four siblings earned university degrees and they are always helping him to deal with the pressures. He always knew he would attend ASU some day, but through summer camps, speakers, physics and math teachers he became interested in engineering. Finally he stated that the CEMS Center and the students are very helpful.

Nekesha is a Chemical engineering major and a commuter student (45 minutes one way). She also works near her home for 20 hours a week. Her time on campus is very limited. However, she says that she does see the benefit of studying in groups and likes the CEMS Center because there are people around to help her and answer her questions. Nekesha's parents did not attend college and although her brother attends a technical institute, her parents still did not know what to expect and do not understand the pressures. Especially important to Nekesha is the fact that "If I did not know 45 other people (like me), I would be lost." She felt that knowing someone else who went through what she is going through helps immensely and that the SBP is the foundation for providing this to her.

\section{Discussion}

The students that participated in the focus groups were all very willing to share their experiences. In general, they all felt that the SBP has provided them the "head start" that the program was intended to do and all found other benefits as well. None of the groups would have evaluated the program as favorably right after the program as they did later during the focus groups [6]. We had assumed that the SBP students had all decided that they would study engineering in the CEAS. However, we learned that prior to the bridge program some had decided on engineering, but not ASU; while others had decided on ASU, but not engineering; and some were not very sure about either. The scholarship offer was critical for the motivation to go to the program, to complete the program, and to attend the CEAS at ASU.

The feedback given by the former Honors College students (too much to do Honors and ECE 100 in the same semester of the freshman year) was taken under advisement and relayed to the Honors College. Now the Honors College and the CEAS are cooperating to make sure that freshman engineering students do not take both of these courses in the same semester.

Starting with the third class, SBP 1998, all of the participants were required to enroll in and attend ASE 194, the Academic Success class. The students from summer '98 all expressed the networking value of the bridge program and the ASE 194 class. Students also mentioned the value of the engineering dorm floors. For more information on the engineering dorm floors administration see Reference 9.

The CEMS model with the MEP Summer Bridge Program seems to be working well for the incoming freshman minority students. The students spoke of the programs as being very helpful. Our retention statistics show that the minority students who participate in the MEP Summer Bridge Program are retained at a much higher rate than those minority students who do not participate in the program [6]. 


\section{Conclusion}

The MEP Summer Bridge Program has been successful in increasing the first year retention of minority engineering freshman both in the university and in the college. We expect to continue this program as long as we can secure the funding to support it. The students reaffirmed the importance of several of our recruiting programs. The several MESA students in the focus groups showed that our path for the support of minority students beginning in the junior high, continuing through high school, then through the MEP Summer Bridge Program, and on through the MEP is working. The focus students also mentioned the value of the engineering dorm floors. The CEAS has had engineering dorm floors for several years and is expanding that program.

Currently, about one-third of the incoming freshman minority engineering students participate in the MEP Summer Bridge Program. It is our goal to serve a larger percentage of the incoming minority engineering freshmen. In particular we wish to target the participation of more Native American students to increase their retention rate to that of the African American and Hispanic engineering freshman students.

Of course, strong support programs for the graduation of the engineering students must follow the focus on freshman retention. The MEP continues to evaluate and reevaluate its retention programs in order to assure this support.

Bibliography

1. National Science Foundation. Women, Minorities, and Persons with Disabilities in Science and Engineering: 1998, Arlington, VA, 1999, (NSF 99-338), p. xv.

2. Ibid. p.xvi.

3. Morrison, Catherine, Griffin, Kenneth, and Marcotullio, Peter, "Retention of Minority Students in Engineering," NACME Research Letter, Volume 5, Number 2, December 1995, p. 1-20.

4. Office of Institutional Analysis, Enrollment and Retention Summaries, Arizona State University, Tempe, Arizona, 1993-1999.

5. Reyes, Maria A., McCartney, Mary Ann, and Anderson-Rowland, Mary R., "Transferring the Knowledge in a Bridge Program: engineering Students become Coaches," Annual Conference Proceedings, American Society for Engineering Education, Milwaukee, Wisconsin, June 1997, Session 2630, CDROM, 7 pages.

6. Reyes, Maria A., Anderson-Rowland, Mary R., and McCartney, Mary Ann, "Student Success: What Factors Influence Persistence?" Frontiers in Education, Conference Proceedings, CDROM, Session 11a5, San Juan, Puerto Rico, November 1999, 11a5-20 to 11a5-28.

7. Anderson-Rowland, Mary R., Reyes, Maria A., and McCartney, May Ann, "MEP Summer Bridge Program: Mathematics Assessment Strategies," ASEE Annual Conference Proceedings, CDROM, Seattle, Washington, June 1998, Session 2670, 10 pages.

8. National Science Foundation. Women, Minorities, and Persons With Disabilities in Science and Engineering: 1994, Arlington, VA, 1994. (NSF 94-333), p. 46-47.

9. Anderson-Rowland, Mary R., "Using a Roommate Preference Survey for Students Living on an Engineering Dorm Floor," Proceedings: Frontiers in Education, $28^{\text {th }}$ Annual Conference, Tempe, Arizona, November 1998, Paper 1225, p. 500-504. 
MARIA A. REYES

Maria A. Reyes is the Director of the Office of Minority Engineering Programs. She is a graduate of the Minority Engineering Program (MEP) at ASU, where she obtained a BS in Civil Engineering and a Master's degree in GeoEnvironmental Engineering. She spent two years as a staff engineer at a local consulting firm. Maria developed the Minority Bridge Program. She also developed and teaches a seminar course for entering minority engineering students. Maria was recently honored with a Student Appreciation Award for staff, one of only six university staff members to be so honored.

\section{MARY R. ANDERSON-ROWLAND}

Mary R. Anderson-Rowland is the Associate Dean of Student affairs and Special Programs in the CEAS at ASU. She earned her Ph.D. from the U. of Iowa. She has received several awards for her support of diversity including the ASU-CEAS Alumni Chapter Honorary SOAR Award for support of Student Organizations in 1999 and the University Achievement in Gender Equity Progress Award, Faculty Women's Association, in 1995. She is the director of a successful Graduate Career Change Program in IE. She is a frequent speaker on the myths of mathematics and engineering and of the career opportunities in engineering, especially for women and minority students.

\section{MARY ANN MCCARTNEY}

Mary Ann McCartney served as the Student Support Liaison Offers as well as the Directory of the OMEP for the CEAS at ASU for five years. Prior to joining ASU, she spent 18 years at IBM serving her last five years as Program Manager of Academic and Community Relations. For two years she served as corporate liaison between IBM and the headquarters of the Mathematics, Engineering, Science Achievement (MESA) Program at UC Berkeley. In late 1999 she assumed a consulting position with the University of California, President's office, supporting the California Statewide MESA program. 